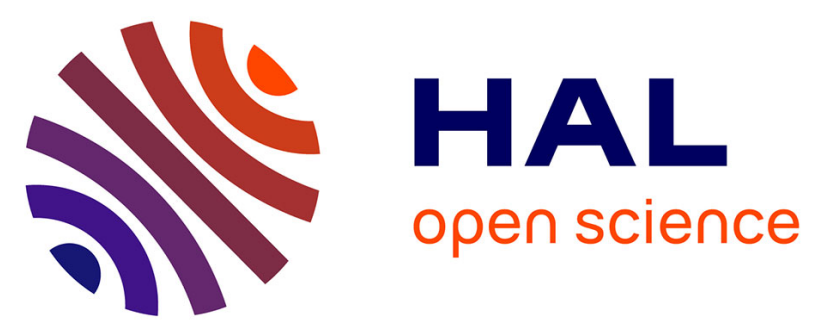

\title{
Broadband modulated absorption/emission technique to probe sooting flames: Implementation, validation, and limitations
}

\author{
A. Guibaud, J.M. Citerne, J.M. Orlac'h, O. Fujita, J.-L. Consalvi, J.L. \\ Torero, G. Legros
}

\section{To cite this version:}

A. Guibaud, J.M. Citerne, J.M. Orlac'h, O. Fujita, J.-L. Consalvi, et al.. Broadband modulated absorption/emission technique to probe sooting flames: Implementation, validation, and limitations. Proceedings of the Combustion Institute, 2019, 37 (3), pp.3959-3966. 10.1016/j.proci.2018.06.199 . hal-02279440

\section{HAL Id: hal-02279440 \\ https://hal.sorbonne-universite.fr/hal-02279440}

Submitted on 5 Sep 2019

HAL is a multi-disciplinary open access archive for the deposit and dissemination of scientific research documents, whether they are published or not. The documents may come from teaching and research institutions in France or abroad, or from public or private research centers.
L'archive ouverte pluridisciplinaire HAL, est destinée au dépôt et à la diffusion de documents scientifiques de niveau recherche, publiés ou non, émanant des établissements d'enseignement et de recherche français ou étrangers, des laboratoires publics ou privés. 


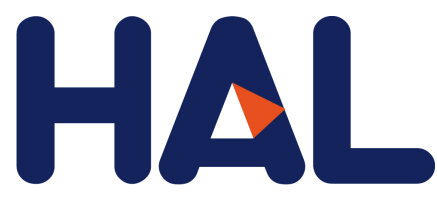

archives-ouvertes

\title{
Broadband modulated absorption/emission technique to probe sooting flames: Implementation, validation, and limitations
}

\author{
A. Guibaud, J.M. Citerne, J Orlac\&apos;h A, O. Fujita, J.-L. Consalvi, J.L.
} Torero, G. Legros, J.M. Orlac'h

\section{To cite this version:}

A. Guibaud, J.M. Citerne, J Orlac\&apos;h A, O. Fujita, J.-L. Consalvi, et al.. Broadband modulated absorption/emission technique to probe sooting flames: Implementation, validation, and limitations. Proceedings of the Combustion Institute, Elsevier, 2019, 37 (3), pp.3959-3966. 10.1016/j.proci.2018.06.199 . hal-02279440

\section{HAL Id: hal-02279440 \\ https://hal.sorbonne-universite.fr/hal-02279440}

Submitted on 5 Sep 2019

HAL is a multi-disciplinary open access archive for the deposit and dissemination of scientific research documents, whether they are published or not. The documents may come from teaching and research institutions in France or abroad, or from public or private research centers.
L'archive ouverte pluridisciplinaire HAL, est destinée au dépôt et à la diffusion de documents scientifiques de niveau recherche, publiés ou non, émanant des établissements d'enseignement et de recherche français ou étrangers, des laboratoires publics ou privés. 


\title{
Broadband modulated absorption/emission technique to probe sooting flames: Implementation, validation, and limitations
}

\author{
A. Guibaud ${ }^{\mathrm{a}, *}$, J.M. Citerne $^{\text {a }}$, J.M. Orlac'h ${ }^{\text {a }}$, O. Fujita ${ }^{\mathrm{b}}$, J.-L. Consalvi $^{\mathrm{c}}$, \\ J.L. Torero ${ }^{\mathrm{d}}$, G. Legros ${ }^{\mathrm{a}}$ \\ a Sorbonne Université, CNRS, UMR 7190, Institut Jean Le Rond d'Alembert, Paris F-75005, France \\ ${ }^{\mathrm{b}}$ Division of Mechanical and Space Engineering, Hokkaido University, Kita13 Nishi8, Kita-ku, Sapporo, Hokkaido \\ 060-8628, Japan \\ ${ }^{\mathrm{c}}$ Aix-Marseille Université, CNRS, UMR 7343, IUSTI 5 rue E. Fermi, 13013 Marseille, France \\ ${ }^{\mathrm{d}}$ Department of Fire Protection Engineering, University of Maryland, College Park, MD 20742, USA
}

Received 1 December 2017; accepted 25 June 2018

Available online xxx

\begin{abstract}
A new optical setup and its associated post-processing have been designed in an effort to map soot related quantities in an axisymmetric flame spreading over solid samples in microgravity environment where setup compactness constraints are stringent. Extending the well-established spectral modulated absorption/emission (S-MAE) technique that uses lasers as light sources together with a sophisticated optical arrangement, LEDs have been associated with broadband optics to enable the broadband modulated absorption/emission (B-MAE) technique. The design and the cautious assessment of the original B-MAE setup are reported in the present paper. Algorithms that need to be reformulated for broadband integration are first validated retrieving both two-dimensional soot temperature and volume fraction fields produced by numerical simulations. Then, these fields are measured with both B-MAE and S-MAE techniques in a largely documented steady laminar non-premixed coflow ethylene/air flame established at normal gravity. Thus, outputs delivered by the B-MAE technique can be compared with those obtained with the S-MAE setup. Both soot temperature and volume fraction are shown to be decently measured by the B-MAE technique. As the spread of the non-buoyant flames to be investigated in the near future is especially driven by radiative heat transfer, the discrepancies between both techniques outputs are commented in the light of the fields of local radiative loss computed from the fields measured by both techniques. As a result, the fields delivered by the B-MAE technique are expected to provide ground-breaking insights into the control of flame spread in the absence of buoyancy, therefore manned spacecraft fire safety.
\end{abstract}

Keywords: Soot; Broadband diagnostic; Soot volume fraction; Soot temperature

\footnotetext{
* Corresponding author.

E-mail address: augustin.guibaud@upmc.fr (A. Guibaud).
} 


\section{Introduction}

Fire spread mechanisms in microgravity environment is still poorly understood [1]. Yet, with the rapid development of ambitious manned missions, which require long travel duration, the risk of a fire-related accident increases dramatically. In the absence of buoyancy forces, most fire detection and control apparatuses developed on earth are inefficient [2]. To get a better understanding of the risks, flame spread rate over solid samples in microgravity has been studied by various methods such as flame front or solid-phase temperature tracking $[3,4]$. Ongoing unique experiments over large flat samples aim at the fine characterization of fire spread over solid samples [5]. Latest reports suggest that intuitions driving the current material standard tests are not valid [6]. These observations are attributed to the shift in predominant heat transfer from natural convection to radiation, as soot residence time in the flame increases $[7,8]$. These conclusions are supported by findings delivered by other experimental setups [9] that have highlighted specific interactions between neighboring flames only revealed in microgravity environment. Still, the radiative properties of the flames, dominated by the continuum spectrum of soot particles [7], have not been properly quantified in non-buoyant flame configurations. Estimations have been performed from local and usually intrusive measurements [5]. An experimental setup able to produce spatially resolved fields over solid samples in microgravity has never been reported. Consequently, a crucial step in the further understanding of flame behavior in microgravity is the development of an optical diagnostic to quantify soot related quantities in the flame. This paper aims at filling this important gap.

Analysis of soot particles formation and release in non-premixed flames at normal gravity is currently a hot topic due to their impact on human health and global warming [10-13]. As a result, a wide range of sophisticated diagnostics has been developed at normal gravity, and could be extended to microgravity environment. To conduct experiments aboard microgravity facilities, constraints in terms of total microgravity duration, safety standards, and overall experimental setup compactness reduce the range of possible designs.

Current state-of-the art laser-based techniques can map soot volume fraction, temperature, and characteristic sizes of soot particles. Laser Induced Incandescence (LII) techniques, widely implemented for both laminar and turbulent flames [14], extract temperature from laser heated soot particles radiation $[15,16]$. This requires a careful characterization of the wavelength dependence of the soot emissivity [17] but ignores some physicochemical processes likely to occur at the surface of the soot during the laser heating, leading to large uncertainties in the evaluation of the actual soot temperature. Also several limitations have been highlighted [18], in particular the difficulty to measure wide areas.

Implemented for droplets in droptower facilities, deconvolution with light-extinction/ gravimetric calibration lacks the corresponding temperature fields required to infer the local radiative balance. Also, 3-color pyrometry was not adopted because the flame is then considered an optically-thin medium [19].

Probing flames with laser energy levels that are non-intrusive, the Modulated Absorption/Emission (MAE) technique [20] is considered. Local spectral soot absorption coefficients are directly evaluated from the laser absorption measurements. Using Mie theory in the Rayleigh limit, the absorption coefficient is converted into the local soot volume fraction using a soot refractive index model. Then soot temperature is evaluated from the ratio of the local spectral emission rates captured within two different spectral ranges. This way, the technique provides self-calibrated temperature measurements that do not dependent on the soot refractive index selected. Recently, the MAE technique was extended to deliver twodimensional axisymmetric fields [21], thus allowing simultaneous measurements of soot temperature and volume fraction distributions over wide areas. This technique is consequently able to convey the information required to quantify radiative heat transfer, but needs a very large experimental setup. A similar yet more compact technique is the Cone Beam Tomographic Three Color Spectrometry (CBT-TCS) [22]. Using a CMOS color camera, red, green, and blue intensities emitted by soot particles are discriminated and maps of soot temperature, volume fraction, and mean particle diameter can then be obtained by comparing the different signals. In contrast with the MAE, CBT-TCS does not account for soot re-absorption along the line-of-sight. As a result, errors can dramatically increase when the flame is optically thick [23], a situation expected in microgravity $[8,24]$.

Combining the pros of the different methods, the approach outlined in the present paper extends the aforementioned spectral MAE (S-MAE) technique to a broadband optical arrangement, referred to as broadband MAE (B-MAE), where the collection of the signals can be performed by a single camera. Sticking to a non-intrusive diagnostic enables the reacting flows to be probed without any perturbation. Among other relevant configurations, non-buoyant flame spread is to be studied over the coating of cylindrical electric wires during parabolic flights [9]. This axisymmetric configuration especially allows for the cylindrical deconvolution procedure associated with the B-MAE technique. In addition, the B-MAE setup has recently delivered promising recordings 
in microgravity, presented in the Supplemental material S1.

Consequently, this paper first presents the theoretical background underlying the B-MAE technique. Then, the associated methodology is carefully assessed step by step and tested against fields delivered by a numerical simulation of a documented configuration, i.e. a buoyant axisymmetric laminar coflow non-premixed ethylene/air flame. Finally, both S-MAE and B-MAE experimental results are contrasted with each other probing a flame established over a Santoro burner. Some key assumptions are then identified. The performance of the B-MAE technique is examined in respect of measuring local radiative loss, since quantifying this effect will significantly aid understanding of flame spread in microgravity.

\section{Broadband modulated absorption/emission technique}

\subsection{Theoretical background}

Details about the basics of the MAE technique and its updated extension to two-dimensional axisymmetric fields can be further found in the papers by Jenkins and Hanson [20] and Legros et al. [21].

Because characteristic times and length scales identified here are of a similar order of magnitude as those of the configuration used for the validation of the S-MAE technique, the same set of assumptions is adopted. This allows for relevant comparisons of resulting soot volume fraction and temperature fields. In particular, scattering is neglected while soot re-absorption is accounted for. The Radiative Transfer Equation (RTE) is integrated along a straight light beam crossing an axisymmetric flame [25]. The energy carried at a given wavelength $\lambda$ and impacting a pixel at a distance $x$ from the optical axis is computed in two situations: either for a flame alone, or for a flame that is probed by an emitting source. In the first case, considering $\kappa_{\lambda}(y)$ the local spectral absorption coefficient and $B_{\lambda}(y)$ the local spectral blackbody radiative intensity, the energy $d \mathcal{E}_{\lambda}^{o}$ collected per unit time over a pixel of surface $S^{p}$ through optics of overall collection efficiency $\eta$ can be approximated as follows:

$d \mathcal{E}_{\lambda}^{o}=S^{p} \eta \int_{y_{m}}^{y_{M}}(\kappa B)_{\lambda}(y) e^{-\int_{y}^{y_{M}} \kappa_{\lambda}\left(y^{\prime}\right) d y^{\prime}} d y$

In this equation, $y$ is the coordinate along the optical pathway crossing the flame between $y_{m}$ and $y_{M}$. The exponential term models the soot-related re-absorption. With an emitting source whose initial intensity per unit area is $\phi_{\lambda}$, an additional flux impinges the pixel and complements $d \mathcal{E}_{\lambda}^{o}$, resulting in $d \mathcal{E}_{\lambda}^{\mid}$:

$d \mathcal{E}_{\lambda}^{\mid}=d \mathcal{E}_{\lambda}^{o}+S^{p} \eta \phi_{\lambda} e^{-\int_{y_{m}}^{y_{M}} \kappa_{\lambda}(y) d y} d \lambda$

From the principle of superposition, the total intensity collected by a pixel of a broadband sensor is the result of spectral integration of $d \mathcal{E}_{\lambda}^{o}$ and $d \mathcal{E}_{\lambda}^{\mid}$, multiplied by the transfer function $f_{\lambda}$ of the optical sensor, what the following equations state:

$\mathcal{E}^{o}=\int_{\lambda} f_{\lambda} d \mathcal{E}_{\lambda}^{o} \quad ; \quad \mathcal{E}^{\mid}=\int_{\lambda} f_{\lambda} d \mathcal{E}_{\lambda}^{\mid}$

The objective is to extract both $\kappa_{\lambda}$ and $B_{\lambda}$ from these equations and to model their dependence with local soot properties. Because the purpose of this paper is not to propose a soot model, details of chemistry are ignored. Soot radiative heat transfer is modeled without requiring any assumptions regarding soot formation, growth and destruction pathways in ethylene chemistry. It is assumed soot particles radiative properties behaves as black bodies radiating in the Rayleigh limit of the Mie theory. The Rayleigh regime of the radiative theory links soot absorption coefficient $\kappa_{\lambda}$ to the soot volume fraction $f_{v}$, while Planck's law links thermal radiation $B_{\lambda}$ of a soot particle to local temperature $T$.

$\kappa_{\lambda}=\frac{6 \pi E f_{v}}{\lambda} \quad$ and $\quad B_{\lambda}=\frac{2 h \pi c^{2}}{\lambda^{5}\left(e^{\frac{h c}{\lambda k T}}-1\right)}$

$E$ being a function of the complex refractive index of soot $m$, which in turn depends on wavelength. Some authors [22] consider an averaged refractive index independent of $\lambda$, because various sets of experiments have led to different profiles of soot refractive index [26,27]. The model of Chang and Chalampopoulos [26], which accounts for the spectral dependence of the refractive index over the range of interest, i.e. from $380 \mathrm{~nm}$ to $710 \mathrm{~nm}$, is considered in the following.

Two difficulties arise when trying to isolate successively $\kappa_{\lambda}$ and $B_{\lambda}$ : (1) the need for absolute measurement of $\eta$; (2) the impossibility to inverse the spectral integration. The first problem is circumvented considering solely ratios of signals, as in the S-MAE technique. The second issue, which is the original level of complexity that the present paper tackles, requires cautious developments detailed below.

\subsection{Methodology}

Two successive deconvolutions are required to recover first the soot volume fraction field $f_{v}$, and then the temperature one $T$. Integrals described in Eqs. (1) and (2) are spatially discretized using the natural pixel grid provided by the camera sensor. Because the flame illustrates an axi-symmetric problem a line-by-line process along the axis of 
symmetry is implemented, and each line is decomposed in concentric layers via an onion-peeling method. Each layer is assumed to have uniform properties. Then iterations are run from the outer layers toward the axis of the flame.

$\kappa_{\lambda}$ is first retrieved by measuring the absorbed signal from the backlight. For a given sensor, the transmission field is obtained by subtracting $\mathcal{E}^{o}$ to $\mathcal{E}$, thus removing the spontaneous emission from the flame, and dividing by the intensity of the backlight in the absence of the flame. $f_{v}$ can be recovered by finding at each point the value that generates a transmission field closest to the experimental data. Because the extinction coefficient is proportional to the soot volume fraction (see Eq. (4)), the unique solution at each layer is isolated by dichotomy search.

Once a two-dimensional map of soot volume fraction is obtained, temperature is the only unknown left and is found by analyzing the emission field. The camera efficiency $\eta$ being unknown, absolute emission cannot be quantified. Consequently, temperature is found from the signal ratio of flame spontaneous emission within two different spectral ranges. Again, the temperature that generates numerical ratios closest to the experimental data is retained at each step. However, the complex impact of temperature on the value on the ratio leads to a more careful numerical optimization. Details about issues encountered are further expressed in Section 5.1.

\subsection{Self-consistency of the method}

Before investigating experimental data, algorithms are tested against $f_{v}$ and $T$ fields produced by a numerical simulation of an axisymmetric laminar non-premixed coflow ethylene/air flame [28] to assess the robustness of the methodology. These fields are shown on the right in Fig. 1. Like for the assessment of the S-MAE technique [21], synthetic frames are computed from the $f_{v}$ and $\mathrm{T}$ fields, then these frames are used as inputs of the methodology outlined in Section 2.2. Figure 1 demonstrates the very good correlations between original and retrieved data, both in terms of soot volume fraction (top) and temperature (bottom). Both quantities are recovered with almost perfect accuracy: volume fraction discrepancies are only round-up errors, and temperature ones are lower than $20 \mathrm{~K}$. Temperature deconvolution uses the recovered soot volume fraction, so temperature errors are only estimated at locations, where $f_{v}$ is higher than $0.1 \mathrm{ppm}$ for a reasonable signal-to-noise ratio.

Maximum temperature discrepancies are located on the central axis, due to the combined effect of a low local soot volume fraction and the accumulation of the round-up errors from the external layers. These errors are negligible as compared to the level of noise expected with the experimental diagnostics.

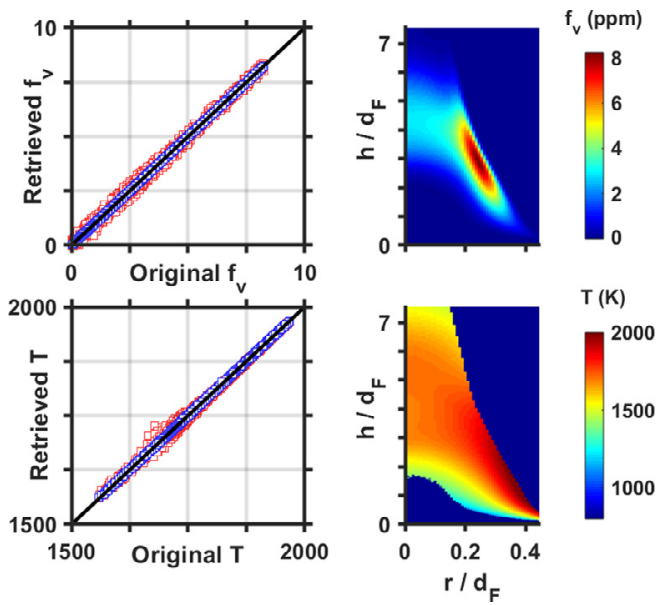

Fig. 1. Data retrieved by B-MAE algorithms as a function of the original data provided by a numerical simulation [28]. Straight black solid lines indicate the ideal locations of the points. Blue dots indicate an ideal noiseless situation, while red dots assume a level of random noise in the process, relevant to that of the optical setup used. On the right, the original fields are displayed in the physical space. $r=0$ is the simulated flame's axis of symmetry, $h$ the height above the coflow burner, and $d_{F}$ the fuel tube inner diameter. (For interpretation of the references to color in this figure legend, the reader is referred to the web version of this article.)

\section{Experimental setup}

\subsection{Flame configuration}

Figure 2 illustrates the B-MAE experimental setup. Within the context of the present study, a steady laminar non-premixed flame is established over a Santoro axisymmetric ethylene/air coflow

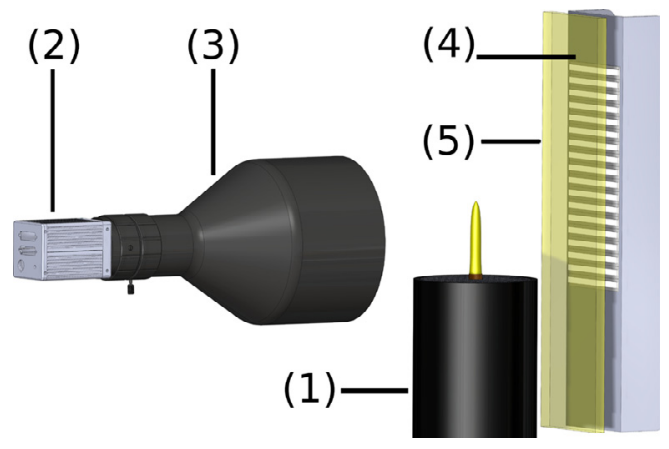

Fig. 2. Schematic of the B-MAE optical arrangement set around a laminar axisymmetric coflow non-premixed flame: (1) burner; (2) tri-CCD camera; (3) telecentric lens; (4) LEDs board; (5) diffusive screen. Due to its compactness, this basic configuration can be readily integrated to a rig of reasonable dimensions. 
burner. Ethylene is injected through the vertical central brass duct, which has a $11 \mathrm{~mm}$ effective diameter $d_{F}$ of injection. The air flow is introduced into the concentric $102 \mathrm{~mm}$ inner diameter brass cylinder. Fuel and air flow rates are set to $0.229 \mathrm{Nl} \mathrm{min}{ }^{-1}$ and $60 \mathrm{Nl} \mathrm{min}{ }^{-1}$, respectively. Both mass flow rates are controlled by Bronkhorst ELFLOW devices. Further details about the burner can be found in [29]. In the following, the vertical burner's axis of symmetry is referred to as $\mathrm{O} h$ and its origin is located at the nozzle exit plane, defining the height above the burner $h$. The cross-stream coordinate is $r$, which is the distance from the axis of symmetry.

\subsection{Optical setup}

The flame is captured using a JAI AT-140CL digital tri-CCD camera that images the incoming light on three different matrices of $512 \times$ 1396 pixels $^{2}$. This set of matrices enables the discrimination of the contributions from the blue $(380 \leq \lambda \leq 510)$, green $(460 \leq \lambda \leq 610)$, and red $(550 \leq \lambda \leq 680)$ spectral bands. The camera is equipped with a telecentric lens that limits the light collection to beams parallel to the optical axis, what the deconvolution process implemented requires. With this arrangement, the spatial resolution of the projected data is $96 \mu \mathrm{m}$ for each spectral band. The spectral sensitivity of each band is carefully established prior to any experiment, using a THR 1000 monochromator with a $5 \mathrm{~nm}$ step. A similar careful spectral profiling is conducted for the backlighting to find the profile $\phi(\lambda)$, also crucial in the equations.

On the opposite side of the camera, a backlighting produced by LEDs is set up. A diffusive screen made of polished polycarbonate is inserted between the LEDs and the flame to homogenize the backlighting intensity. The LEDs are selected to make the backlighting spectrum and that of the flame as similar as possible, thus allowing for an optimized use of every CCD dynamics range. The intensity of the backlighting is tuned by adjusting the current flowing through the LEDs.

To obtain the absorption and emission fields that are the inputs of the B-MAE methodology, four frames are required, imaging the flame with backlight $I_{F, L}$, the flame without backlight $I_{F, L 0}$, the backlight without flame $I_{F 0, L}$, and the background noise $I_{F 0, L 0}$. Reminding the ambitious goal to obtain time-resolved fields along flame spread, the analysis is performed using only one $I_{F, L}$ and one $I_{F, L 0}$ frames. Static data $I_{F 0, L}$ or $I_{F 0, L 0}$ are averaged over 50 acquisitions to restrict the noise influence. Given the spectral profile of the flame spontaneous emission, the exposure times for the blue $\left(t_{\text {expo }}^{B}\right)$, green $\left(t_{\text {expo }}^{G}\right)$, and red $\left(t_{\text {expo }}^{R}\right)$ sensors are adjusted separately to allow for maximum signal amplitude in each spectral range. Settings for the

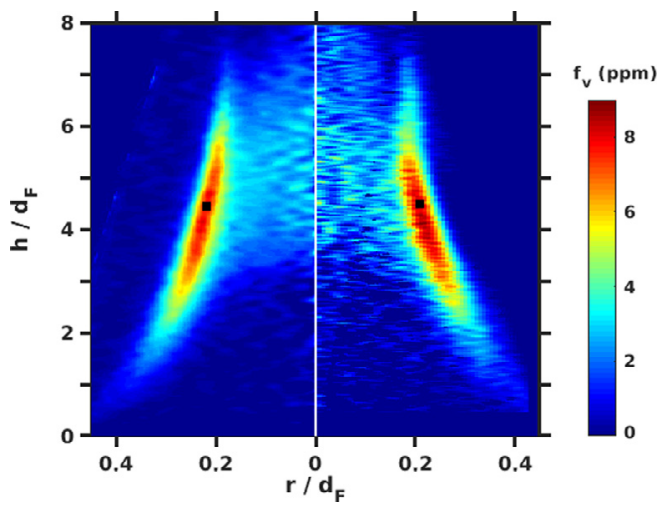

Fig. 3. Soot volume fraction fields obtained using the SMAE technique (left) and the B-MAE one (right). Black dots indicate the locations of the peak $f_{v}$.

present validation are $t_{\text {expo }}^{R}=225 \mu \mathrm{s}, t_{\text {expo }}^{G}=751 \mu \mathrm{s}$, and $t_{\text {expo }}^{B}=6.76 \mathrm{~ms}$.

This new optical setup is tested against the SMAE technique [21]. It is worth mentioning that the S-MAE camera has a higher spatial resolution, i.e. $36 \mu \mathrm{m} /$ pixel, and each image processed is the average over 100 successive frames.

\section{Comparison with S-MAE}

The soot volume fraction fields are obtained from the local absorption coefficient field delivered at $\lambda=645 \mathrm{~nm}$ by the $\mathrm{S}$-MAE technique on one hand, and by the red CCD sensor of the B-MAE setup on the other hand, in order to compare data extracted from similar spectral ranges. Temperature is obtained considering ratios between data obtained at 785 and $645 \mathrm{~nm}$ for the S-MAE technique, and between data delivered by the red and green bands for the B-MAE diagnostic.

\subsection{Soot volume fraction}

The fields of soot volume fractions are displayed in Fig. 3. Both methods deliver very similar fields, though the S-MAE one produces slightly higher soot volume fraction. This difference can be explained by the arbitrary choice of spectral dependence of the soot coefficient $E$, which has a direct impact on soot volume fraction given Eq. (4) and its integration over the red band required by the BMAE method.

Looking now at the overall topology, the BMAE method recovers properly all the main features of the distribution, i.e. a thin region of higher soot volume fraction on the wing close to the flame sheet, a peak at approximatively the same height (46.31 mm for S-MAE versus $45.60 \mathrm{~mm}$ for B-MAE), and values on the central axis that increase gradually with the height above the burner. 


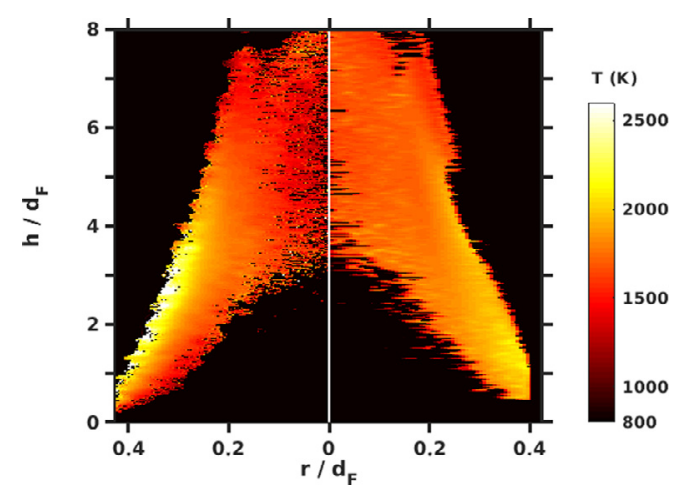

Fig. 4. Temperature fields obtained using the S-MAE technique (left) and the B-MAE one (right).

The B-MAE approach displays more intense highfrequency spatial fluctuations that can be possibly filtered out by regular signal processing strategies.

\subsection{Soot temperature}

The soot temperature fields are shown in Fig. 4. Both fields show similar gradients directed downwards and toward the centerline. The B-MAE technique overestimates the temperature near the central axis, yet within an acceptable range. In addition, the obvious difference in external contours is not relevant as it concerns pixels with negligible soot volume fraction.

The two methods do not have the same spatial discretization due to different cameras. As a result, errors cannot be quantified through the direct evaluation of local discrepancy between both fields. Consequently, populations of soot temperature/volume fraction measurements in flames are reported in Fig. 5. The higher B-MAE temperatures are located roughly $50 \mathrm{~K}$ above those of the SMAE technique but in a region of low $f_{v}$. The peak soot volume fractions hardly differ from each other, given the S-MAE uncertainty of $\pm 0.5 \mathrm{ppm}$. Ultimately, these discrepancies may hardly affect the field of local radiative losses.

\subsection{Radiative losses}

To quantify the local radiative loss, the divergence of the radiative flux at every location where soot volume fraction and temperature are measured can be computed. To do so, the RTE is solved in its non-scattering formulation for the radiative intensity $I_{\lambda}$ using the Finite Volume Method proposed by Chui et al. [30] for axisymmetric coordinates with a $12 \times 16$ angular mesh. For the laminar ethylene/air flames investigated, radiation by soot over the whole spectrum was found to prevail over that by gaseous species [24]. Consequently, the contributions of gaseous products (mainly $\mathrm{CO}_{2}$ and

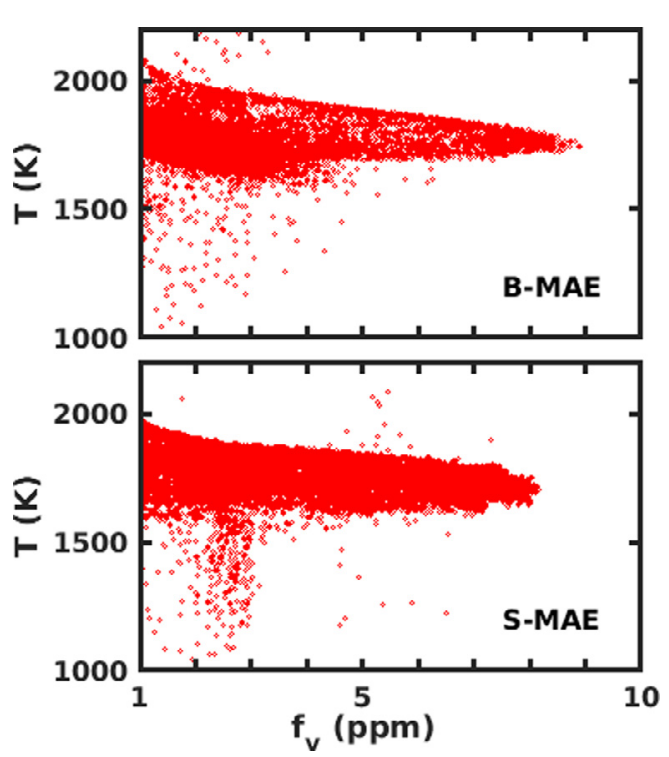

Fig. 5. Populations of soot temperature/volume fraction measurements in the flame. Only locations with soot volume fraction over $1 \mathrm{ppm}$ and local radiative loss above $20 \%$ of the peak are selected as trustworthy data.

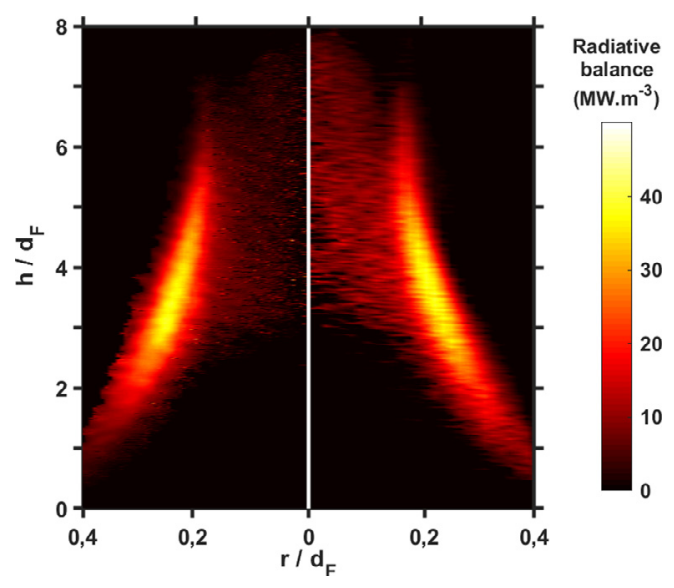

Fig. 6. Fields of local soot-related radiative loss obtained using the S-MAE data (left) and the B-MAE ones (right).

$\mathrm{H}_{2} \mathrm{O}$ ) can be neglected. Thus, the numerical computations require a model for the spectral dependence of $E$ (see Eq. (4)). Again, the model of Chang and Charalampopulos [26] is selected.

The fields of local radiative loss are shown in Fig. 6. These are in good agreement with each other, as the temperature gaps recorded near the axis are weighted by the low level of soot volume fraction in this region. It can be concluded that the B-MAE provides information that are accurate enough to decently assess the radiative heat transfer in the flames investigated. 


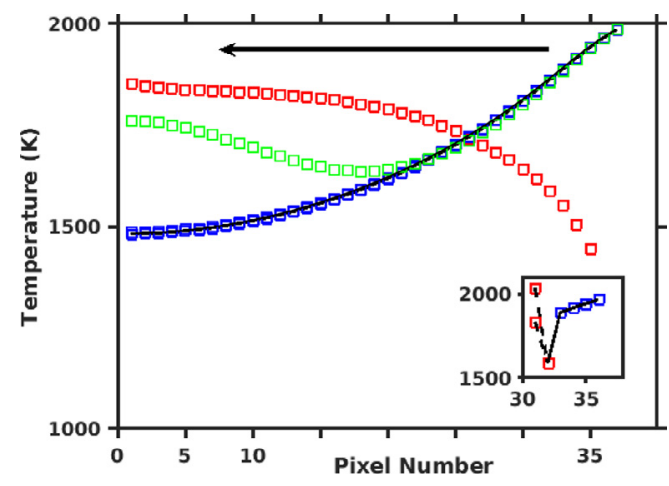

Fig. 7. At a given height, temperature deconvolution is performed from peripheral pixel layers toward center $(x=0)$. Black line represents the original field. Blue dots indicate the physical solution and red dots the second mathematical solution. The inset displays the unrealistic local temperature drop allowing for the systematic identification of a deviation of the algorithm at pixel 33 here. At this position, the other potential temperature is automatically selected. Green dots indicate the solution obtained if re-absorption is ignored. Results sharply diverge near the axis of the flame. (For interpretation of the references to color in this figure legend, the reader is referred to the web version of this article.)

\section{Discussion}

The B-MAE data processing described above is a quite straightforward extension of the existing S-MAE deconvolution process. Nevertheless, two major theoretical points are worth being highlighted to account for the main difficulties addressed.

\subsection{Re-absorption}

Re-absorption by soot along the collection lineof-sight has led to a dramatic increase in complexity of the algorithms. However, given the high soot volume fraction expected in microgravity environment, developing a procedure that takes reabsorption into account was mandatory to avoid major errors, especially in the inner layers of the flame. Re-absorption coupled with broadband integration leads to an issue that has not been reported yet - to the authors' knowledge - when investigating temperature. As color ratios are considered, two temperatures are mathematical solutions of the minimization problem. Though two distinct temperatures lead to two different signals in both red and green spectral ranges, they can result in the same red/green signal ratio once re-absorption is considered. Because though the green signal is expected to grow faster as temperature increases due to the $\lambda$ dependency of $B$, it is also the signal that is the most damped by re-absorption as $\kappa \sim 1 / \lambda$. Figure 7 illustrates for a profile extracted from the numerical flame investigated in Section 2.3 a tricky situation where the two solutions are at some locations so close that noise can mislead the deconvolution algorithm. Starting from the most outer layer, which is not affected by the re-absorption issue, the algorithm finds a unique temperature $T_{0}$, then from pixel to pixel only the mathematical solution closest to $T_{0}$ is kept. If the algorithm ever deviates to the virtual solution, the temperature drop shown in the inset of Fig. 7 reveals. In such a case, and should the drop value be over a threshold temperature difference corresponding to experimental noise quantification, the algorithm is sent back to previous pixels where it can recapture the physical solution.

\subsection{Influence of size parameter}

Ref. [22] discusses the influence of the Rayleigh limit on absorption efficiency. At the lowest wavelengths of the blue channel (around $380 \mathrm{~nm}$ ), the B-MAE underlying assumptions stipulating that (1) soot particles radiate in the Rayleigh regime and (2) scattering is neglected are not valid everywhere in the flame, as the ratio $x=\pi d / \lambda$, where $d$ is a characteristic diameter of the size distribution, increases along the flame height [31]. Assuming primary particles diameter of $40 \mathrm{~nm}$ from TEM experiments [32] and $380 \mathrm{~nm}<\lambda<680 \mathrm{~nm}$ implies $0.18<x<0.33$. The deviation from the Mie model is reasonable as long as $x$ is below 0.3 , i.e. $\lambda>$ $420 \mathrm{~nm}$. As a result, only red and green CCDs data are considered in the present analysis. Analyzing data from the blue spectral band would require additional information on soot particles such as a characteristic length or structural feature. The lack of this information does not tarnish the scope of the present study as particle size distribution hardly affects the evaluation of the local radiative balance that is especially dominated by the contributions at large wavelength, i.e. at relatively small size parameter.

Moreover, the selection of the soot refractive index model may not be as controversial as expected provided that measurements only serve to compare local radiative properties of flames spreading on solid samples under different external conditions of oxygen concentration, oxidizer flow rate or pressure for instance. As a result, adopting an arbitrary but single model is not a rough approximation. Soot particles are treated as independent monodisperse primary particles. As this first simple step proves to be consistent, quantification of polydisperse particles or fractal aggregates that requires more sophisticated hardware could be worth developing.

\section{Conclusion}

The performances of the new B-MAE technique have been assessed with some success. Both twodimensional fields of soot temperature and volume 
fraction are very similar to those delivered by the original S-MAE technique when a steady buoyant laminar coflow ethylene/air non-premixed flame is probed. It is worth noticing that the discrepancies between the S-MAE and B-MAE fields are of the order of magnitude of the uncertainties attributed the S-MAE technique, i.e. $\pm 50 \mathrm{~K}$ for temperature and $\pm 0.5 \mathrm{ppm}$ for soot volume fraction.

As these fields are expected to provide crucial inputs for a finer evaluation of the radiative heat transfer that governs flame spread over solid samples in microgravity, they have been used as inputs for the computation of the local radiative losses in the aforementioned buoyant flame. Although discrepancies reveal in regions of low soot volume fraction and/or low temperature, the major contributions to the flame radiative losses are captured. As a result, new and finer information to predict potential fire spread rate over different materials should be soon delivered. The B-MAE experimental setup has already been implemented in a microgravity test rig to study flame spread over the coating of cylindrical wires.

\section{Supplementary material}

Supplementary material associated with this article can be found, in the online version, at doi:10. 1016/j.proci.2018.06.199.

\section{References}

[1] I. Bolodian, A.K. Melikhov, L. Tanklevskiy, Acta Astronaut. 135 (2017) 100-108.

[2] G. Ruff, Halon Options Tech. Working Conf. (2001) $13-22$.

[3] X. Zhao, Y.T. Liao, M.C. Johnston, J.S. Tien, P.V. Ferkul, S.L. Olson, Proc. Combust. Inst. 36 (2017) 2971-2978.

[4] M. Nagachi, F. Mitsui, J.M. Citerne, H. Dutilleul, A. Guibaud, G. Jomaas, G. Legros, N. Hashimoto, O. Fujita, Proc. Comb. Inst. 37 (2018) in press, Corrected proof

[5] G. Jomaas, J.L. Torero, C. Eigenbrod, et al., Acta Astronaut. 109 (2015) 208-216.

[6] J.W. Marcum, S.L. Olson, P.V. Ferkul, in: International Conference on Environmental Systems, 47, 2017.
[7] H.D. Ross, in: Microgravity Combustion: Fire in Free Fall, Academic Press, Cambridge, U.S.A., 2001, p. 401. Comb. Series.

[8] G. Legros, J.L. Torero, Proc. Combust. Inst. 35 (2015) 2545-2553.

[9] J.M. Citerne, H. Dutilleul, K. Kizawa, et al., Acta Astronaut. 126 (2016) 500-509.

[10] M. Frenklach, Phys. Chem. Chem. Phys. 4 (2002) 2028-2037.

[11] Q. Wang, G. Legros, J. Bonnety, et al., Combust. Flame 183 (2017) 242-252.

[12] A. Stampfl, M. Maier, R. Radykewicz, P. Reitmeir, M. Göttlicher, R. Niessner, ACS Nano 5 (2011) 5345-5353.

[13] R.A. Kerr, Science 339 (2013) 382.

[14] T. Ni, J.A. Pinson, S. Gupta, R.J. Santoro, Appl. Opt. 34 (1995) 7083-7091

[15] S. Schraml, S. Dankers, K. Bader, S. Will, A. Leipertz, Combust. Flame 120 (2000) 439-450.

[16] F. Liu, D.R. Snelling, K.A. Thomson, G.J. Smallwood, Appl. Phys. B 96 (2009) 623-636.

[17] F. Goulay, P.E. Schrader, H.A. Michelsen, Appl. Phys. B 100 (2010) 655-663.

[18] F. Liu, D.R. Snelling, K.A. Thomson, G.J. Smallwood, Appl. Phys. B 96 (2009) 623-636.

[19] T. Panagiotou, Y. Levendis, M. Delichatsios, Combust. Flame 104 (1996) 272-287.

[20] T.P. Jenkins, R.K. Hanson, Combust. Flame 126 (2001) 1669-1679.

[21] G. Legros, Q. Wang, J. Bonnety, M. Kashif, C. Morin, J.-L. Consalvi, F. Liu, Combust. Flame 162 (2015) 2705-2719.

[22] H. Zhao, B. Williams, R. Stone, J. Quant, Spectrosc. Radiat. Transf. 133 (2014) 136-152.

[23] F. Liu, K.A. Thomson, G.J. Smallwood, Combust. Flame 160 (2013) 1693-1705.

[24] R. Demarco, F. Nmira, J.L. Consalvi, J. Quant, Spectrosc. Radiat. Transf. 120 (2013) 52-69.

[25] M.F. Modest, Radiative Heat Transfer, Academic Press, Cambridge, U.S.A., 2003, p. 263.

[26] H. Chang, T.T. Charalampopoulos, Math. Phys. Sci. 430 (1990) 577-591.

[27] R. Viskanta, M.P. Mengüq, Prog. Energy Combust. Sci. 13 (1987) 97-160.

[28] T. Blacha, M.D. Domenico, P. Gerlinger, M. Aigner, Combust. Flame 159 (2012) 181-193.

[29] G. Legros, T. Gomez, M. Fessard, et al., Proc. Combust. Inst. 33 (2011) 1095-1103.

[30] E.H. Chui, G.D. Raithby, P.M.J. Hughes, J. Thermophys. Heat Transf. 6 (1992) 605-611.

[31] B. Zhao, Z. Yang, M. Johnston, H. Wang, A. Wexler, M. Balthasar, Combust. Flame 133 (2003) 173-188.

[32] P.M. Anderson, H. Guo, P.B. Sunderland, J. Aerosol. Sci. 114 (2017) 317-326. 